\title{
Synthesis and virtual screening of bis-(4-(tert-butyl)-N- (methylcarbamothioyl) benzamide)-Iron (III) complex as an anticancer candidate
}

\author{
Ruswanto*1, Winda Trisna Wulandari ${ }^{1}$, Indah Cantika ${ }^{1}$, Richa Mardianingrum ${ }^{2}$

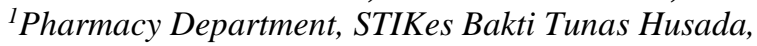 \\ Jl. Cilolohan No. 36 Kota Tasikmalaya,West Java, Indonesia \\ ${ }^{2}$ Pharmacy Department, Universitas Perjuangan, \\ Jl. Peta No. 177 Kota Tasikmalaya, West Java, Indonesia
}

Accepted: 12-03-2021

\begin{abstract}
Thiourea derivatives were much used in drug discovery and drug-making, such as for an anticancer. The formation of drug complexes can increase lipophilicity through chelation formation, and the drug action is significantly upward due to the effective permeability to the center. In another study, the alteration of the compound becomes the complex with metal will grow in its activity so recently we have synthesized the Bis-(4-(Tert-Butyl)-N-(Methylcarbamothioyl) Benzamide)-Iron (III) complex. The synthesis of Fe (III) metal with the 4-(Tert-Butyl)-N(Methylcarbamothioyl) Benzamide in ethanol by reflux at $75^{\circ} \mathrm{C}$ for 7 hours. Hot Stage Microscopy, UV-Visible Spectrophotometry Infrared Spectrophotometry, and Massa Spectrophotometry were used to characterize the complex. This study concerns representing, inferring, and predicting pharmacokinetics and toxicity and molecular docking complexes. The complex weight was 0.29469 g. Its purity has been tested using the melting point determination and has obtained its range was $113^{\circ}-115^{\circ} \mathrm{C}$. The Characteristics of Bis-(4-(Tert-Butyl)-N-(Methylcarbamothioyl) Benzamide)Iron(III) complex have a maximum wavelength of $260 \mathrm{~nm}$ and provide absorption of Fe-O vibrations at wavenumbers $478.2 \mathrm{~cm}^{-1}$ and $588 \mathrm{~cm}^{-1}$, and the $\mathrm{m} / \mathrm{z}$ complex of spectrophotometry mass was 559.31. The molecular docking process was performed using AutodockTools-1.5.6 software. It showed that Bis-(4-(Tert-Butyl)-N-(Methylcarbamo-thioyl)Benzamide)-Iron(III) complex could interact with ribonucleotide reductase enzyme, and it has better interaction than the 4-(Tert-Butyl)-N-(Methylcarbamothioyl)Benzamide with the binding affinity energy $(\Delta \mathrm{G})$ of -8.52 $\mathrm{kcal} / \mathrm{mole}$ and the constant inhibition (Ki ) of $568.55 \mathrm{nM}$.
\end{abstract}

Keywords: Complex, Docking, Fe (III), Synthesis, 4-(Tert-Butyl)-N-(Methylcarbamothioyl) Benzamide

\footnotetext{
*Corresponding author:

Ruswanto

Pharmacy Department, STIKes Bakti Tunas Husada,

J1. Cilolohan No. 36 Kota Tasikmalaya, West Java, Indonesia

Email: ruswanto@stikes-bth.ac.id
} 


\section{INTRODUCTION}

The World Health Organization (WHO) defines cancer as a large group of diseases that occur because cells grow beyond normal limits. Cancer can spread and infect other parts of the body. The disease has many anatomical and molecular subtypes, each of which requires special treatment. Based on global data in 2018, cancer is the second largest killer with an estimated 9.6 million deaths. (Organization, 2018; RI, 2019).

Thiourea is described as an organic compound containing carbon, nitrogen, hydrogen, and sulfur atoms. Thiourea has a similar structure to urea, but it has an $\mathrm{S}$ atom which replaces the $\mathrm{O}$ atom in the urea structure. In previous studies, drug discovery researches were frequently use urea as an anticancer. (Lan et al., 2018; Ren et al., 2014), anti-tuberculosis (Brown et al., 2011; North et al., 2013), antimalarial (Domínguez et al., 2005; Schwartz et al., 2015) and as an analgesic (Sartori et al., 1994). Thiourea is considerably used as a discovery of new drugs for anticancer and antitumor (Karakuş et al., 2009; Manjula et al., 2009; Pingaew et al., 2018; Yang et al., 2013; Yao et al., 2012), antibacterial, antimicrobial, and anti-tuberculosis (Bielenica et al., 2018; Binzet et al., 2018; Khan et al., 2008; Seth et al., 2004; Upadhayaya et al., 2009; Vega-Pérez et al., 2012) soluble epoxide hydrolase inhibitor and also as an antiviral (Burmistrov et al., 2018).

In the previous study, we have synthesized an in vitro test to cancer cells of the 4-(tert-butyl)$\mathrm{N}$-(methylcarbamothioyl) benzamide the IC-50 of $111 \mu \mathrm{g} / \mathrm{mL}$. The 4-(tert-butyl)-N(methylcarbamothioyl) benzamide is a compound derived from 1-benzoyl-3-methylthiourea (Ruswanto et al., 2018). One of the many advances to drug production is to convert compounds into metal complexes, making their absorption and distribution and their pharmacological activities better (Lin et al., 2008; Mardianingrum et al., 2019; Ruswanto et al., 2019).

The findings of anticancer drugs is done by synthesizing a complex between 4- (Tert-Butyl) -N-Methylcarbamothioyl) Benzamide with Fe (III) metal. It is a new compound in the thiourea derivative. Those were described and characterized using Hot Stage Microscopy (HSM), Infrared Spectrophotometry, UV-Vis Spectrophotometry, Mass Spectrophotometry, Molecular Docking, ADME Toxicity Prediction.

\section{MATERIALS AND METHOD \\ Materials and instruments}

We used graduated cylinder, watch glass, analytical scales, Erlenmeyer Bulb, reflux sets, magnetic stirrers, thermometers, filter paper, hot plates, $50 \mathrm{~mL}$ and $100 \mathrm{~mL}$ beakers, crucible, 30 $\mathrm{mL}$ vials, Hot Stage Microscopy, UV-Vis Spectrophotometer, Genesys 10S, Perkin Elmer Spectrum 100 FT-IR Spectrometer, and Mass Spectrophotometry (MS). The laptop we used having hardware specifications with AMD Ryzen 3 2200U specifications with Radeon Vega Mobile Gfx (4 CPUs), 2.5GHz 4GB 64-bit RAM. And its software were ChemDraw Ultra 12.0, MarvinSketch 5.2, AutodockTools-1.5.6, Discovery Molecular Viewer 16.1, Molegro Molecular Viewer 2.5, and PreADMET.

The materials, we used the 4-(tert-butyl)-N-(methylcarbamothioyl)benzamide, ethanol p.a, $\mathrm{FeCl}_{3} .6 \mathrm{H}_{2} \mathrm{O}$ p.a, Bis-(4-(tert-butyl)-N-(methylcarbamothioyl) benzamide)-Iron (III) complex, Dimethyl sulfoxide (DMSO), and 2EUD.pdb.

\section{Synthesis of metal complex}

The 4-(tert-butyl)-N-(methyl carbomethyl)benzamide as much as 0.992 moles liquefied in $30 \mathrm{~mL}$ ethanol (solution A) and 0.496 moles of metal $\mathrm{FeCl}_{3} \cdot 6 \mathrm{H}_{2} \mathrm{O}$ in ethanol (solution $\mathrm{B}$ ), then it (B) was dropped into solution A little by little. The drip process was under low heating and done gradually. For about 7 hours at $75^{\circ} \mathrm{C}$ we reflux it while stirring it using a magnetic stirrer. After that, we evaporate it slowly (Mardianingrum et al., 2019). 


\section{The purity test with hot stage microscopy}

The Bis-(4-(tert-butyl)-N-(methylcarbamothioyl) benzamide)-Iron (III) complex on the slide was set on a hot stage. Then the temperature is gradually increased at a constant speed, and the melting process is observed with a polarization microscope (Šimek et al., 2014).

\section{UV-Vis spectrophotometry}

DMSO with a concentration of $100 \mathrm{ppm}$ and $200 \mathrm{ppm}$, is used to dematerialize standards and samples. Then used the electronic spectrum from a UV-Vis spectrophotometer to measure it in the $200 \mathrm{~nm}-800 \mathrm{~nm}$ area, and the absorbance was observed based on the maximum wavelength (Ruswanto et al., 2019).

\section{Infrared spectrophotometry}

The next process is to take $5 \mathrm{mg}$ of $\mathrm{KBr}$ powder to be crushed on a mortal until homogeneous crushed. A cleaned pellet maker which has been dried with chloroform, ready to be used to make pellets transparently. The resulting pellets were then measured in the $4400-400 \mathrm{~cm}^{-1}$ wave area to be used as spectra (Ruswanto et al., 2018).

\section{Mass spectrophotometer (MS)}

MS settings were executed on capillary $3 \mathrm{kV}$, sampling cone 20, Extraxtion Cone 2, source temperature 120, Desolvation temperature 250, Flow Cone gas 50 L / hour, Flow Desolvation Gas $800 \mathrm{~L} /$ hour, and sampling flow 20 micro L / min. Figure 4 presents the mass spectrum. The molecular ion peak at $\mathrm{m} / \mathrm{z} 559.31$, equal to the complex molecular weight, which was detected in the mass spectrum of Bis- (4- (tert-butyl) -N- (methylcarbamothioyl) benzamide) -Iron (III) (Mardianingrum et al., 2019).

\section{Molecular docking}

AutodockTools-1.5.6 software was used to create ligands with receptors. Then using 2EUD to retrieve ribonucleatide reductase enzyme data from the PDB website http://rcsb.org (Xu et al., 2006). This was done to obtain the value of root-mean-square-deviation (RMSD), Gibbs free energy $(\Delta \mathrm{G}) /$ binding affinity for compounds/ ligands and complex compounds. After that, observing the interaction of receptors with ligands and receptors with complex compounds, and using Discovery Studio software version 16.1 to create its 2D visualization (Pal et al., 2019).

\section{PREADMET and toxicity}

The process was continued by utilizing PreADMET, a web-based application on http://preadmet.bmdrc.org/. After the structure of the compound was converted into molfile *.mol (molfile) format, PreADMET will calculate the predicted absorption for Caco2 cells, HIA (Human Intestinal Absorption), plasma protein binding (PPB) and their toxicity parameters through the Ames test automatically. (Rozano et al., 2017; Yamashita et al., 2000; Yee, 1997; Zhao et al., 2001).

\section{RESULT AND DISCUSSION}

Synthesis of the Bis-(4-(tert-butyl)-N-(methylcarbamothioyl) benzamide)-Iron (III) Complex Ligands are electron pair donors. Each atom has a lone pair that coordinates covalently with the iron. The iron that was reacted to become a ligand will become complex, with the ratio of mole metal:ligand is $1: 2$. One of them must be significantly larger so that the equilibrium of the reaction changes to the right because $\mathrm{FeCl}_{3} \cdot 6 \mathrm{H}_{2} \mathrm{O}$ can react absolutely with 4-(tert-butyl)-N(methylcarbamothioyl)benzamide. The result of the reaction scheme is in Figure 1. 


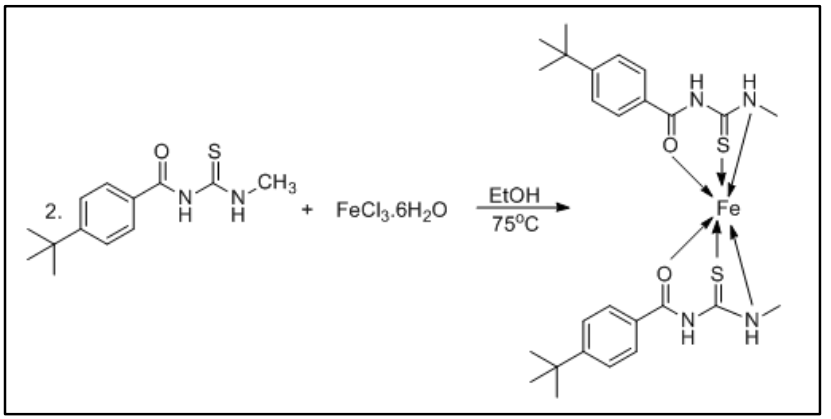

Figure 1. The reaction proposed of ligand and iron (III)

The reflux process needed 7 hours at $75^{\circ} \mathrm{C}$. For better results, the process must be longer. The stirring process used a magnetic stirrer. The process will cause the particles to collide with each other, thereby affecting the increase in the kinetic energy of the molecules.

To obtain crystals complex, the reflux result was then slowly evaporated. It was reached $85.85 \%$ in powder and brownish-yellow.

\section{The purity test results}

The melting point distance check was used to make sure that the compound produced was a new and not a starting material. The compound was assumed to be pure if the melting point difference reach about $2^{\circ} \mathrm{C}$. Check on Table 1 for the result.

Table 1. Melting point of the compounds

\begin{tabular}{ll}
\hline \multicolumn{1}{c}{ Compounds } & Melting point $\left({ }^{\circ} \mathbf{C}\right)$ \\
\hline 4-(tert-butyl)- $N$-(methylcarbamothioyl)benzamide & $109-111$ \\
Bis-(4-(tert-butyl)- $N$-(methylcarbamothioyl)benzamide)-Iron $($ III $)$ & $113-115$ \\
\hline
\end{tabular}

The melting point diversion between the synthesis product and a starting material can illustrate that the new compound has been synthesized powerfully, and it was predicted as the complex.

\section{Characterization and Identification of Complex}

As the first structure, the synthesized compounds (MS) were then characterized and identified structurally using IR spectrophotometry, UV-Vis spectrophotometry, and mass spectrophotometry. That was done to set the maximum shift in wavelength to release the spectral profile of it, which it was then compared to the spectral profile of compound 4-(tert-butyl)-N(methylcarbamothioyl)benzamide and Bis-(4-(tert-butyl)-N-(methylcarbamothioyl) benzamide)Iron-benzamide (III). Then the results were obtained as in Table 2 which shows the value of the maximum wavelength ( $\lambda$ max) absorbance (A) of the compounds in the DMSO solvent and Figure 2 , which is an overlay of the UV-Vis spectra of the starting material and the complex. 
Table 2. UV-Visible spectrum results

\begin{tabular}{llc}
\hline \multicolumn{1}{c}{ Compounds } & Absorbance & $\lambda$ max (nm) \\
\hline \multirow{2}{*}{$\mathrm{FeCl}_{3} \cdot 6 \mathrm{H}_{2} \mathrm{O}$} & 3.602 & 243.00 \\
& 3.626 & 243.00 \\
\multirow{2}{*}{ 4-(tert-butyl)- $N$-(methylcarbamothioyl)benzamide } & 3.602 & 240.00 \\
\hline \multirow{2}{*}{ Bis-(4-(tert-butyl)- $N$-(methylcarbamothioyl) } & 1.117 & 281.00 \\
benzamide)-Iron(III) & 1.116 & 281.00 \\
& 1.117 & 281.00 \\
\hline
\end{tabular}

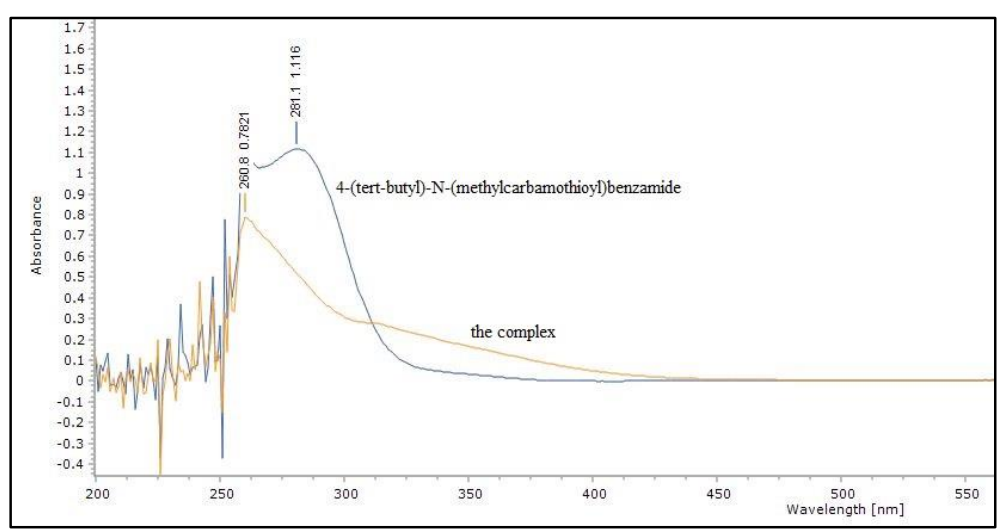

Figure 2. The overlay of the UV-Vis spectra of the starting material and the complex

The hypochromic shift occurs due to a more polar solvent that is moving $n \rightarrow \pi^{*}$ where the organic molecule has an unsaturated functional group so that the double bonds in the group provide the required $\pi$ orbitals. The ground state in some of the transitioning particles becomes more polar than the excited state. (Santos et al., 2015). There is a shift in the maximum wavelength towards the smaller or hypochromic (blue shift) spectrum of $\mathrm{Fe}^{3+}(260.00 \mathrm{~nm})$ from the $\mathrm{FeCl}_{3} \cdot 6 \mathrm{H}_{2} \mathrm{O}$ solution to the $\mathrm{Fe}^{3+}$ spectrum from Bis-(4-(tert-butyl)-N-(methylcarbamothioyl)benzamide) Iron (III) solution. This indicates a complex formation.

Table 3 shows the size of $\lambda_{\max }$ shift, absorbance (A) and molar absorption $(\varepsilon)$, and cleavage energy (10 Dq) of the Bis-(4-(tert-butyl)-N-(methylcarbamothioyl)benzamide) Iron (III) complex.

Table 3. Electronic spectrum and value $10 \mathrm{Dq}$ [13]

\begin{tabular}{lccccc}
\hline \multicolumn{1}{c}{ Compound } & $\begin{array}{c}\mathbf{M r} \\
(\mathbf{g} / \mathbf{m o l})\end{array}$ & $\begin{array}{c}\lambda_{\max } \\
(\mathbf{n m})\end{array}$ & $\begin{array}{c}\mathbf{v} \\
\left(\mathbf{c m}^{-\mathbf{1}}\right)\end{array}$ & $\mathbf{A}$ & $\begin{array}{c}\boldsymbol{\varepsilon} \\
\left(\mathbf{L} \cdot \mathbf{m o l}^{-\mathbf{1}} \mathbf{c m}^{-\mathbf{1}}\right)\end{array}$ \\
\hline $\mathrm{FeCl}_{3} \cdot 6 \mathrm{H}_{2} \mathrm{O}$ & 270 & 242.00 & 41322.314 & 3.602 & 4878.378 \\
4-(Tert-Butyl)-N-(Methylcarbamothioyl)Benzamide & 250.36 & 281.00 & 35587.188 & 1.117 & 1329.365 \\
Bis-(4-(Tert-Butyl)-N-(Methylcarbamothioyl)Benzamide)-Iron(III) & 556.56 & 260.00 & 38461.538 & 0.805 & 2150.309 \\
\hline
\end{tabular}

The next test is infrared spectrophotometry which was carried out to obtain functional group information on the synthetic compounds produced. This complex showed that the $\mathrm{C}=\mathrm{O}$ vibration absorption is located in $1627 \mathrm{~cm}^{-1}$, which the vibration frequency decreased due to the mesomeric effect. Based on the theory, the $\mathrm{C}=\mathrm{C}$ vibration absorption is in $1680-1600 \mathrm{~cm}^{-1}$, while the $\mathrm{C}-\mathrm{N}$ bond strain absorption is at $1326 \mathrm{~cm}^{-1}$. The absorption of metal vibrations with the $\mathrm{O}$ group of the ligand will also appear at the wave number $600-400 \mathrm{~cm}^{-1}$. Based on the theory, the metal vibration 
absorption with an $\mathrm{O}$ group of the ligands will appear at a wavenumber of $600-400 \mathrm{~cm}^{-1}$. The Fe-O vibration absorption analysis result of the complex compound Bis-(4-(Tert-Butyl)-N(Methylcarbamothioyl)Benzamide)-Iron (III) appeared in the $478.2 \mathrm{~cm}^{-1}$ and $588 \mathrm{~cm}^{-1}$, and The Fe$\mathrm{N}$ vibration absorption analysis result of the complex compound Bis-(4-(Tert-Butyl)-N(Methylcarbamothioyl)Benzamide)-Iron (III) appeared in the $356.5 \mathrm{~cm}^{-1}$ (Rao and Venkataraghavan, 1962; Santos et al., 2015; Saratovskikh et al., 2013; Wang and Andrews, 2006). Table 4 shows the infrared data, and Figure 3 shows the infrared spectrum data.

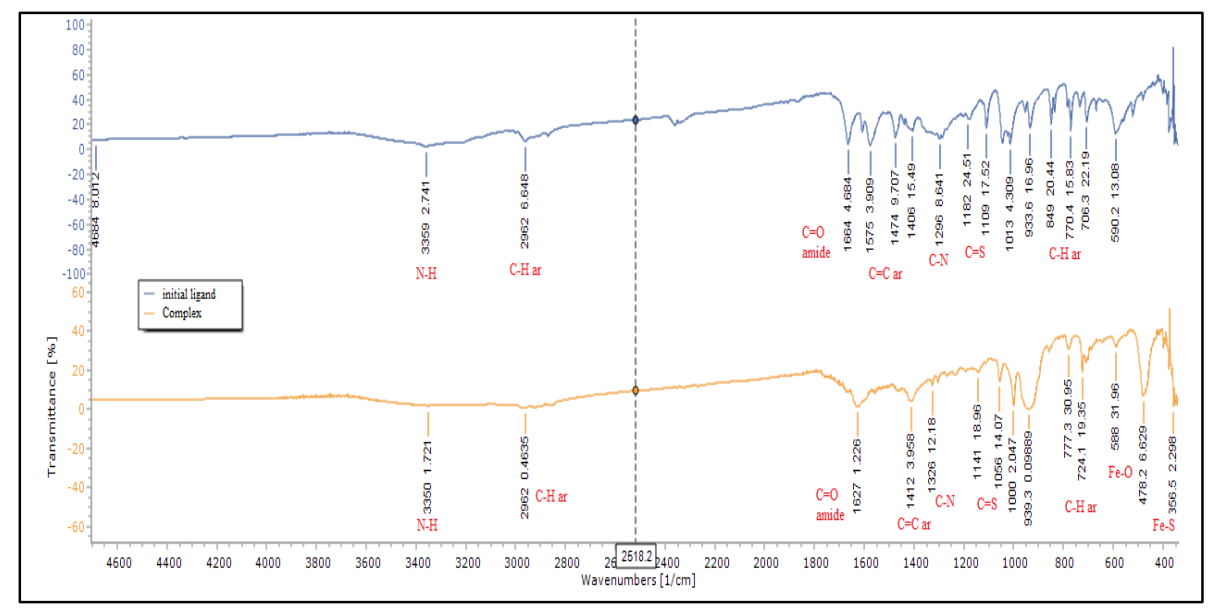

Figure 3. Infrared Spectrum for the ligand 4- (Tert-Butyl) -N- (Methylcarbamothioyl) Benzamide (blue); the Infrared Spectrum for the Bis- (4-(Tert-Butyl)-N(Methylcarbamothioyl) Benzamide) -Iron (III ) complex (Orange)

Table 4. The comparison of infrared data for Bis- (4- (Tert-Butyl) -N- (Methylcarbamothioyl) Benzamide) -Iron (III) and 4- (Tert-Butyl) -N- (Methylcarbamothioyl) Benzamide complex

\begin{tabular}{|c|c|c|}
\hline \multirow[b]{2}{*}{$\begin{array}{l}\text { Functional } \\
\text { Groups }\end{array}$} & \multicolumn{2}{|r|}{$\mathrm{v}\left(\mathrm{cm}^{-1}\right)$} \\
\hline & $\begin{array}{c}\text { 4-(Tert-Butyl)- } N \text { - } \\
\text { (Methylcarbamothioyl)Benzamide }\end{array}$ & $\begin{array}{c}\text { Bis-(4-(Tert-Butyl)-N- } \\
\text { (Methylcarbamothioyl)Benzamide)-Iron(III) }\end{array}$ \\
\hline NH stretch & 3359 & 3350 \\
\hline $\mathrm{C}=\mathrm{O}$ amide & 1664 & 1627 \\
\hline $\mathrm{C}=\mathrm{C}$ aromatic & 1474 & 1412 \\
\hline C-N amine & 1296 & 1326 \\
\hline $\mathrm{Fe}-\mathrm{O}$ & - & $588 ; 478$ \\
\hline $\mathrm{Fe}-\mathrm{S}$ & - & 356 \\
\hline
\end{tabular}

The next characterization was Mass Spectrophotometry (MS). It proved that the Bis-(4-(TertButyl)-N-(Methylcarbamothioyl) Benzamide) -Iron (III) complex was obtained in a pure condition. In Figure 3, we can see that the result of molecular ion peak has an $\mathrm{m} / \mathrm{z}$ value of 559.31 . Theoretically, the calculation of the complex molecular weight is 556.56. It indicates that the complex compounds from the one-step acylation synthesis are by the approximate structure in Figure 3. 


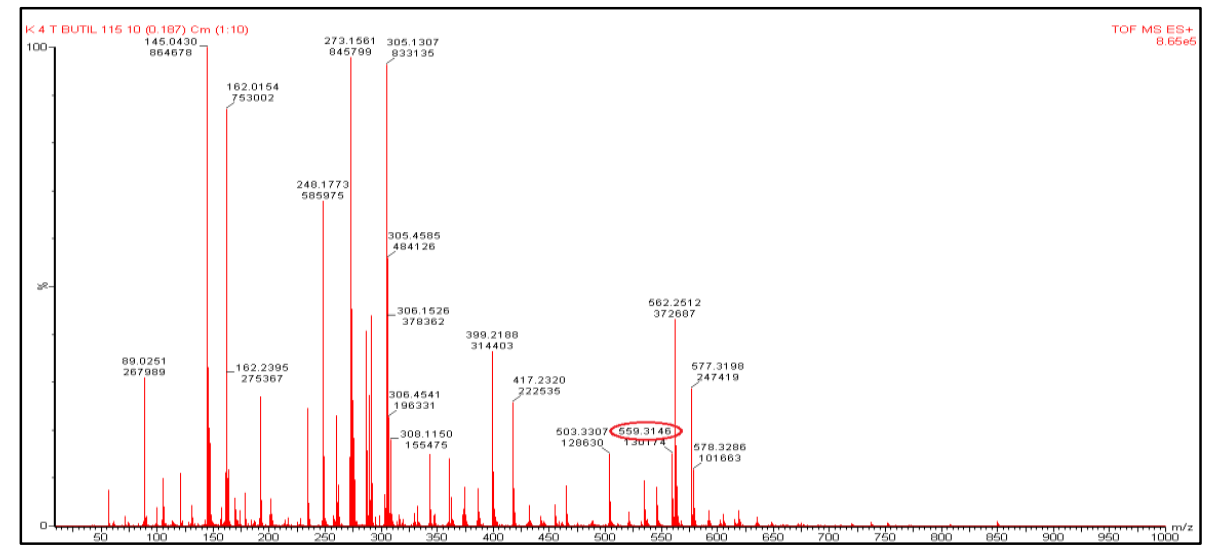

Figure 3. Molecular mass spectrum analysis of Bis- (4- (Tert-Butyl) -N(Methylcarbamothioyl) Benzamide) -Iron (III) Complex Compounds

Based on the characterization in IR and MS spectrophotometry, the approximate structure of the Bis-(4-(Tert-Butyl)-N-(Methylcarbamothioyl)Benzamide) -Iron (III) complex is shown in Figure 4. In this study, the complex's crystal structure has been described and it will not be discussed further here. However, the metal ion is coordinated to $\mathrm{N}, \mathrm{O}$ and S-chelating anionic ligands for this complex and exhibits a distorted square planar geometry of coordination. (Do Couto Almeida et al., 2016).

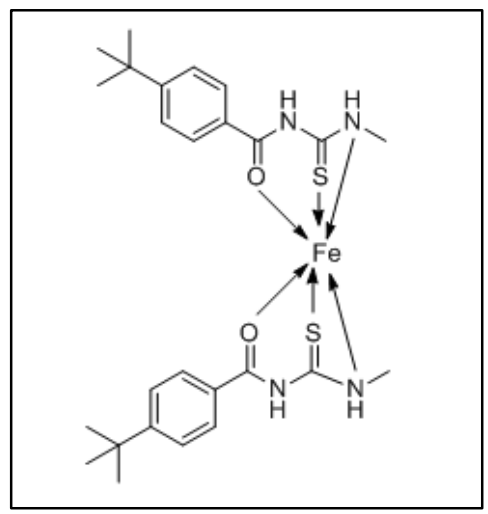

Figure 4. The proposed of the Bis-(4-(Tert-Butyl)-N (Methylcarbamothioyl) Benzamide)-Iron (III) structure complex

From Figure 4 we will find the formation between 4-(Tert-Butyl) -N- (Methylcarbamothioyl) Benzamide with $\mathrm{Fe}$ (III) metal which occurs in $\mathrm{O}, \mathrm{S}$, and one $\mathrm{N}$ groups of $\mathrm{NH}_{2}$, from the lone electron pair derived from of these atoms, and used to bond with the metal $\mathrm{Fe}$ (III) to form the Bis(4-(Tert-Butyl)-N (Methylcarbamothioyl) Benzamide)-Iron (III).

\section{Complex molecular docking}

In the molecular docking process, the first step we must prepare the 4-(Tert-Butyl)-N(Methylcarbamothioyl) Benzamide ligand and the receptors (2EUD.pdb) (Xu et al., 2006). Molecular docking aims to predict the conformation of bond and binding affinity. The Gibbs free energy $(\Delta \mathrm{G})$ value/ binding affinity will be pull out from the docking process. This process was carried out using AutodockTools-1.5.6 software between Bis- (4-(Tert-Butyl)-N-(Methylcar bamothioyl) Benzamide) -Iron (III) ligands with anticancer receptors. This process has several 
stages, including ligand preparation, receptor preparation, validation of the docking method, docking of test ligands against the target receptor, analysis of docking results, PreADMET test. The recapitulation of docking results can be check in Table 5.

Table 5. Recapitulation of docking result

\begin{tabular}{cll}
\hline Compounds & $\begin{array}{c}\text { Binding } \\
\text { affinity } \\
(\mathbf{k c a l} / \mathbf{m o l})\end{array}$ & Inhibition constant \\
\hline Natural ligands 2EUD & -8.23 & $32.21 \mu \mathrm{M}$ \\
4-(Tert-Butyl)-N-(Methylcarbamothioyl)Benzamide & -6.47 & $18.03 \mu \mathrm{M}$ \\
Bis-(4-(Tert-Butyl)-N- & -8.52 & $568.55 \mathrm{nM}$ \\
(Methylcarbamothioyl)Benzamide)-Iron(III) & & \\
\hline
\end{tabular}

The complex compound Bis- (4- (Tert-Butyl) -N- (Methylcarbamothioyl) Benzamide) -Iron (III) has a binding affinity of $-8.52 \mathrm{kcal} . \mathrm{mol}$ and an inhibition constant of $-8.52 \mathrm{kcal} . \mathrm{mol} 568.55$ $\mathrm{nM}$. This is lower than the native ligand or 4- (Tert-Butyl) -N- (Methylcarbamothioyl) Benzamide. The differences were in the value of the binding affinity and the inhibition constant. Therefore, Table 5 concludes that the produced complex compounds are predicted to have the most stable interactions.

Table 6 explains the interaction between the ligand 4-(Tert-Butyl)-N-(Methylcarbamothioyl) Benzamide with amino acid residues at the receptor and the Bis-(4-(Tert-Butyl)-N(Methylcarbamothioyl) Benzamide) -Iron (III) complex with amino acid residues.

Table 6. The interaction between ligands with amino acid residues

\begin{tabular}{ccc}
\hline Compounds & Hydrophobic Bond & Hydrogen Bond \\
\hline Native ligand & ALA 245, GLY 247, LEU & GLY 246, SER 217, \\
& 427, MET 606, PRO 607, L & CYS 218, THR 608, \\
& YS 292, PHE 206, PRO 203, & ALA 609, SER 610, \\
& TYR 155, ALA 201 & THR 611, SER 202. \\
& & ASN 291 \\
4-(Tert-Butyl)-N- & & ARG 293, \\
(Methylcarbamothioyl)Benzamide & ALA 296, GLY 247, PRO & GLY 246, SER 202 \\
& 203, SER 217, ALA 201, & \\
Bis-(4-(Tert-Butyl)-N- & ALA 245, LYS 292, PHE & 206, GLU 430 \\
(Methylcarbamothioyl)Benzamide)-Iron(III) & 203, ALA 201, THR 611, & \\
& ALA 296, TYR 742, PHE & \\
& 403, THR 608, LEU 445, & \\
& SER 217, ALA 609, PRO & \\
& 607, MET 606, GLY 290, & \\
& LYS 292, SER 154, TYR 741 & \\
\end{tabular}

Pharmaciana Vol. 11, No. 1, March 2021, Page. 1 - 14 

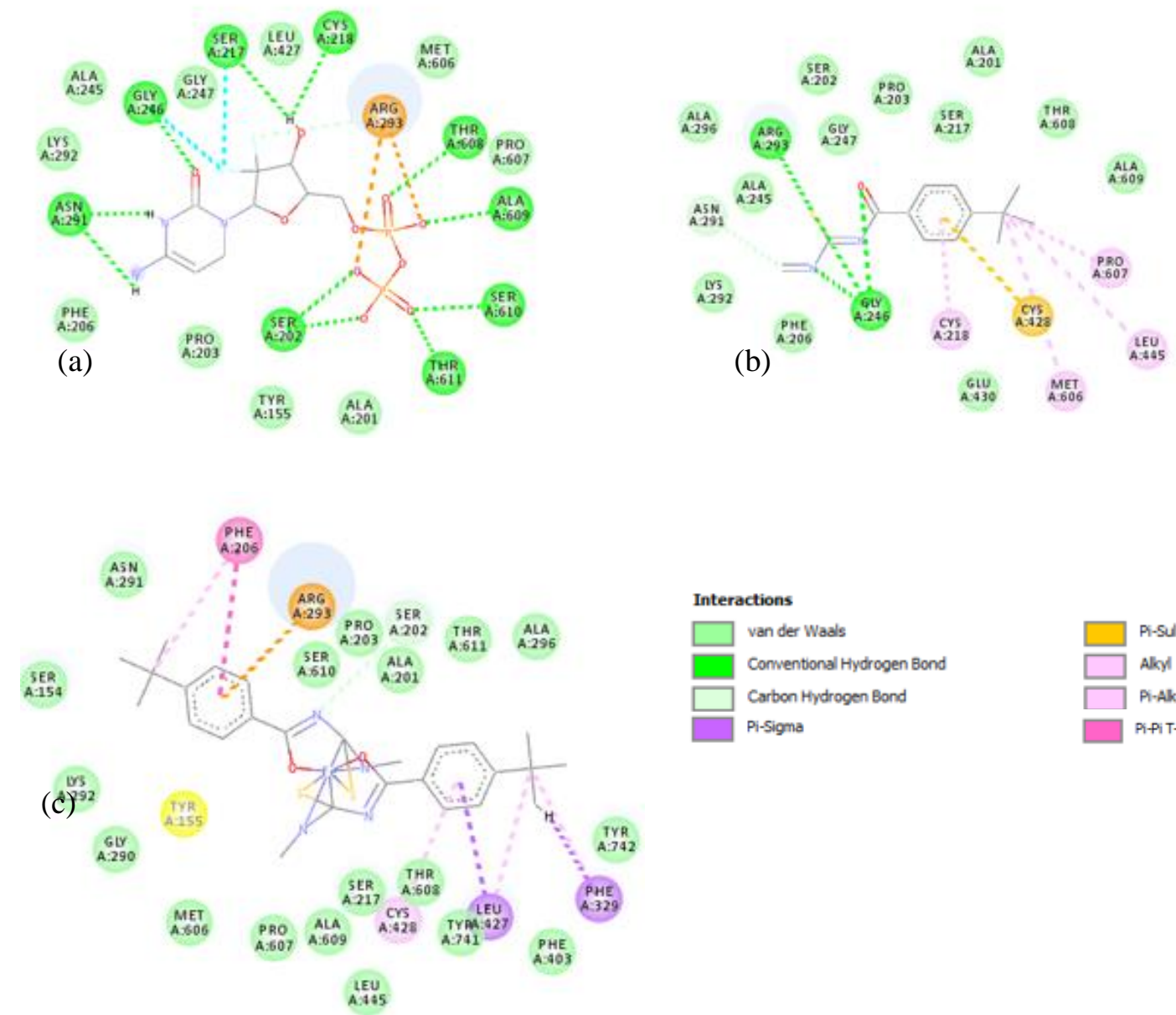

Figure 5. The 2D visualization of native ligand (a), the 2D visualization of 4-(Tert-Butyl) - (Methylcarbamothioyl) Benzamide (b), the 2Dvisuzlization of Bis-(4- (TertButyl)-( Methylcarbamothioyl) Benzamide) -Iron (III) complex (c)

Table 6 and Figure 5 explained that the amino acid residue that interacts the hydrogen bond with all compounds is SER 202, while the amino acids that have the most hydrophobic interactions are with complex compounds (about 18 amino acid residues: ASN 291, SER 610, PRO 203, ALA 201, THR 611, ALA 296, TYR 742, PHE 403, THR 608, LEU 445, SER 217, ALA 609, PRO 607, MET 606, GLY 290, LYS 292, SER 154, TYR 741). Meanwhile, 3 amino acid residues interact hydrophobically with all compounds, namely PRO 203, ALA 20 and LYS 292.

The Bis-(4-(Tert-Butyl)-N-(Methylcarbamothioyl) Benzamide)-Iron (III) complex was tested for ADME (Absorption and Distribution) and toxicity using PreADMET server, which can be read at https://preadmet.bmdrc.kr/. The purpose of the ADME test is to shape the pharmacokinetic profile of the complex. 
Table 7. The prediction of ADME and toxicity results

\begin{tabular}{lcccc}
\hline \multirow{2}{*}{ Compounds } & \multicolumn{2}{c}{ Absorption } & Distribution & Toxicity \\
\cline { 2 - 3 } & HIA $(\%)$ & $\begin{array}{c}\text { caco-2 } \\
\text { PPm/sec) }\end{array}$ & $\begin{array}{c}\text { PPB }(\%) \\
\text { Ames Test }\end{array}$ \\
\hline $\begin{array}{l}\text { 4-(Tert-Butyl)- } N \text { - } \\
\text { (Methylcarbamothioyl)Benzamide }\end{array}$ & 93.865 & 25.6117 & 92.643 & Mutagen \\
$\begin{array}{l}\text { Bis-(4-(Tert-Butyl)-N- } \\
\text { (Methylcarbamothioyl)Benzamide)-Iron(III) }\end{array}$ & 97.83 .87 & 24.128 & 100 & Mutagen \\
\hline
\end{tabular}

Classification: HIA (\%) 0-20 = not well absorbed. 20-70 = moderately absorbed. 70-100 = well absorbed; Caco-2 $(\mathrm{nm} / \mathrm{sec})<4=$ low permeability. $4-70=$ moderate permeability. $>70=$ high permeability; PPB $(\%)>90=$ strongly bound. $<90=$ weakly bound.

Plasma protein binding (PPB) value is more than 90\%. It caused the Bis- (4- (Tert-Butyl) $\mathrm{N}$ - (Methylcarbamothioyl) benzamide) -Iron (III) complex and its comparison compounds have strong bonds with plasma proteins. It can be said to be lacking in distribution. In HIA, it is in the well-absorbed category, and based on $\mathrm{Caco} 2$ it has moderate permeability. All of these are presented in Table 7.

Permeability coefficient as permeability to Caco2 single-layer cell culture, not only related to hydrogen bonding capacity and ionic charge, but also lipophilicity. Permeability is a function of various Physico-chemical parameters, namely permeability $=\mathrm{f}$ (lipophilicity, molecular size, hydrogen-bonding capacity, and charge). Descriptors have a positive correlation with\% HIA. Those are the number of rotational bonds (Nrot), number of hydrogen bond donor groups (Hdon), number of hydrogen bond acceptor groups (Hacc), logarithm of octanol-water partition coefficient (Log P) and logarithm of solubility coefficient (Log S). Plasma protein binding (PPB) is a fraction of the available drug in free form for distribution to various tissues. Human plasma contains $70 \%$ protein, with albumin (HAS, human serum albumin), $\alpha-1$-glycoprotein acid (AGP, alpha-acyd glycoprotein), and lipoproteins as the main components. It is easier to bind with acidic or neutral drugs, whereas AGP and lipoproteins with essential medications.

The toxicity parameter can be find from the mutagenic properties of the tested compound. Mutagens are compounds that can increase the rate of changes or mutations in genes so that they can trigger cancer development (Nursamsiar et al., 2016). The results of toxicity prediction using the PreADMET program showed that the Bis-(4-(Tert-Butyl)-N-(Methylcarbamothioyl) Benzamide) -Iron (III) complex and its comparators had mutagenic properties. Although these compounds are mutagenic, they can still be used as drug candidates at the right dosages (Yamashita et al., 2000; Yee, 1997; Zhao et al., 2001).

\section{CONCLUSION}

We concluded that the Bis-(4-(Tert-Butyl)-N-(Methylcarbamothioyl) Benzamide ) -Iron (III) complex could be synthesized from the reaction between the 4-(Tert-Butyl)-N(Methylcarbamothioyl) Benzamide with $\mathrm{FeCl}_{3} \cdot 6 \mathrm{H}_{2} \mathrm{O}$, and the complex yield was obtained by $85.85 \%$.

We analyzed the molecular docking and concluded that the complex's interaction was better than the initial ligand, so the complex could be used as an anticancer candidate.

\section{REFERENCES}

Bielenica, A., Drzewiecka-Antonik, A., Rejmak, P., Stefańska, J., Koliński, M., Kmiecik, S., Lesyng, B., Włodarczyk, M., Pietrzyk, P., \& Struga, M. (2018). Synthesis, structural and antimicrobial studies of type II topoisomerase-targeted copper(II) complexes of 1,3disubstituted thiourea ligands. Journal of Inorganic Biochemistry, 182, 61-70. 
https://doi.org/10.1016/j.jinorgbio.2018.01.005

Binzet, G., Gumus, I., Dogen, A., Flörke, U., Kulcu, N., \& Arslan, H. (2018). Nickel(II) and copper(II) complexes of N,N-dialkyl-N'-3-chlorobenzoylthiourea: Synthesis, characterization, crystal structures, Hirshfeld surfaces and antimicrobial activity. Journal of Molecular Structure, 1161, 519-529. https://doi.org/10.1016/j.molstruc.2018.02.073

Brown, J. R., North, E. J., Hurdle, J. G., Morisseau, C., Scarborough, J. S., Sun, D., Korduláková, J., Scherman, M. S., Jones, V., Grzegorzewicz, A., Crew, R. M., Jackson, M., McNeil, M. R., \& Lee, R. E. (2011). The structure-activity relationship of urea derivatives as antituberculosis agents. Bioorganic \& Medicinal Chemistry, 19(18), 5585-5595. https://doi.org/10.1016/j.bmc.2011.07.034

Burmistrov, V., Morisseau, C., Pitushkin, D., Karlov, D., Fayzullin, R. R., Butov, G. M., \& Hammock, B. D. (2018). Adamantyl thioureas as soluble epoxide hydrolase inhibitors. Bioorganic \& Medicinal Chemistry Letters, 28(13), 2302-2313. https://doi.org/10.1016/j.bmcl.2018.05.024

Do Couto Almeida, J., Marzano, I. M., Pivatto, M., Lopes, N. P., Da Costa Ferreira, A. M., Pavan, F. R., Silva, I. C., Pereira-Maia, E. C., Von Poelhsitz, G., \& Guerra, W. (2016). Synthesis, cytotoxic and antitubercular activities of copper(II) complexes with heterocyclic bases and 3hydroxypicolinic acid. Inorganica Chimica Acta, 446, 87-92. https://doi.org/10.1016/j.ica.2016.03.005

Domínguez, J. N., León, C., Rodrigues, J., Gamboa de Domínguez, N., Gut, J., \& Rosenthal, P. J. (2005). Synthesis and Evaluation of New Antimalarial Phenylurenyl Chalcone Derivatives. Journal of Medicinal Chemistry, 48(10), 3654-3658. https://doi.org/10.1021/jm058208o

Karakuş, S., Güniz Küçükgüzel, Ş., Küçükgüzel, İ., De Clercq, E., Pannecouque, C., Andrei, G., Snoeck, R., Şahin, F., \& Faruk Bayrak, Ö. (2009). Synthesis, antiviral and anticancer activity of some novel thioureas derivedfrom N-(4-nitro-2-phenoxyphenyl)-methanesulfonamide. European Journal of Medicinal Chemistry, 44(9), 3591-3595. https://doi.org/10.1016/j.ejmech.2009.02.030

Khan, S. A., Singh, N., \& Saleem, K. (2008). Synthesis, characterization and in vitro antibacterial activity of thiourea and urea derivatives of steroids. European Journal of Medicinal Chemistry, 43(10), 2272-2277. https://doi.org/10.1016/j.ejmech.2007.12.012

Lan, J., Huang, L., Lou, H., Chen, C., Liu, T., Hu, S., Yao, Y., Song, J., Luo, J., Liu, Y., Xia, B., Xia, L., Zeng, X., Ben-David, Y., \& Pan, W. (2018). Design and synthesis of novel C14-ureatetrandrine derivatives with potent anti-cancer activity. European Journal of Medicinal Chemistry, 143, 1968-1980. https://doi.org/10.1016/j.ejmech.2017.11.007

Lin, P. Z., Chun, L. C., Zhou, J., Ming, X. L., \& Yan, J. W. (2008). Synthesis, crystal structure and antitumor study of an iron(III) complex of 2-acetylpyrazine N(4)-methylthiosemicarbazone. Zeitschrift Fur Naturforschung - Section B Journal of Chemical Sciences, 63(11), 1257-1261. https://doi.org/10.1515/znb-2008-1103

Manjula, S. N., Malleshappa Noolvi, N., Vipan Parihar, K., Manohara Reddy, S. A., Ramani, V., Gadad, A. K., Singh, G., Gopalan Kutty, N., \& Mallikarjuna Rao, C. (2009). Synthesis and antitumor activity of optically active thiourea and their 2-aminobenzothiazole derivatives: A novel class of anticancer agents. European Journal of Medicinal Chemistry, 44(7), 29232929. https://doi.org/10.1016/j.ejmech.2008.12.002

Mardianingrum, R., Susanti, \& Ruswanto, R. (2019). Bis(N'-(3chlorobenzoyl)isonicotinohydrazide)iron(III) Complex. Molbank, 2020(1), M1101. https://doi.org/10.3390/M1101

North, E. J., Scherman, M. S., Bruhn, D. F., Scarborough, J. S., Maddox, M. M., Jones, V., Grzegorzewicz, A., Yang, L., Hess, T., Morisseau, C., Jackson, M., McNeil, M. R., \& Lee, R. E. (2013). Design, synthesis and anti-tuberculosis activity of 1-adamantyl-3-heteroaryl ureas with improved in vitro pharmacokinetic properties. Bioorganic \& Medicinal 
Chemistry, 21(9), 2587-2599. https://doi.org/10.1016/j.bmc.2013.02.028

Nursamsiar, Toding, A. T., \& Awaluddin, A. (2016). Studi in silico senyawa turunan analog kalkon dan pirimidin sebagai antiinflamasi: prediksi absorpsi, distribusi dan toksisitas. Pharmacy, 13(1), 92-100.

Organization, W. H. (2018). Global Cancer Report 2018. Geneva.

Pal, S., Kumar, V., Kundu, B., Bhattacharya, D., Preethy, N., Reddy, M. P., \& Talukdar, A. (2019). Ligand-based Pharmacophore Modeling, Virtual Screening and Molecular Docking Studies for Discovery of Potential Topoisomerase I Inhibitors. Computational and Structural Biotechnology Journal, 17, 291-310. https://doi.org/10.1016/j.csbj.2019.02.006

Pingaew, R., Prachayasittikul, V., Anuwongcharoen, N., Prachayasittikul, S., Ruchirawat, S., \& Prachayasittikul, V. (2018). Synthesis and molecular docking of N,N'-disubstituted thiourea derivatives as novel aromatase inhibitors. Bioorganic Chemistry, 79, 171-178. https://doi.org/10.1016/j.bioorg.2018.05.002

Rao, C. N. R., \& Venkataraghavan, R. (1962). The C=S stretching frequency and the "-N-C=S bands" in the infrared. Spectrochimica Acta, 18(4), 541-547. https://doi.org/10.1016/S03711951(62)80164-7

Ren, F., Zhong, Y., Mai, X., Liao, Y. J., Liu, C., Feng, L. H., Sun, W., Zen, W. Bin, Liu, W. M., Liu, J., \& Jin, N. (2014). Synthesis and Anticancer Evaluation of Benzyloxyurea Derivatives. Chemical and Pharmaceutical Bulletin, 62(9), 898-905. https://doi.org/10.1248/cpb.c1400305

RI, K. (2019). Hari Kanker Sedunia 2019. Kementerian Kesehatan Republik Indonesia.

Rozano, L., Abdullah Zawawi, M. R., Ahmad, M. A., \& Jaganath, I. B. (2017). Computational Analysis of Gynura bicolor Bioactive Compounds as Dipeptidyl Peptidase-IV Inhibitor. Advances in Bioinformatics, 2017, 1-16. https://doi.org/10.1155/2017/5124165

Ruswanto, R., Mardianingrum, R., Lestari, T., Nofianti, T., \& Siswandono, S. (2018). 1-(4Hexylbenzoyl)-3-methylthiourea. Molbank, 2018(3), M1005. https://doi.org/10.3390/M1005

Ruswanto, R., Sarwatiningsih, Y., Pratita, A., Indra, \& Dewi, R. (2019). Synthesis and Characterization of $\mathrm{Fe}$ (III) Complex with N'- (3-Nitrobenzoyl)Isonicotinohydrazide as an Anti-tuberculosis Candidate. Journal of Physics: Conference Series, 1179, 012136. https://doi.org/10.1088/1742-6596/1179/1/012136

Santos, A. F. M., Macedo, L. J. A., Chaves, M. H., Espinoza-Castañeda, M., Merkoçi, A., Lima, F. das C. A., \& Cantanhêde, W. (2015). Hybrid Self-Assembled Materials Constituted by Ferromagnetic Nanoparticles and Tannic Acid: a Theoretical and Experimental Investigation. Journal of the Brazilian Chemical Society. https://doi.org/10.5935/0103-5053.20150322

Saratovskikh, E. A., Psikha, B. L., \& Sanina, N. A. (2013). The reaction of the iron thiosulfatenitrosyl complex with adenosine triphosphoric acid. Natural Science, 05(07), 800-810. https://doi.org/10.4236/ns.2013.57097

Sartori, E., Camy, F., Teulon, J., Camborde, F., Meignen, J., Hertz, F., \& Cloarec, A. (1994). Synthesis and analgesic activities of urea derivatives of $\alpha$-amino-N-pyridyl benzene propanamide. European Journal of Medicinal Chemistry, 29(6), 431-439. https://doi.org/10.1016/0223-5234(94)90070-1

Schwartz, B. D., Skinner-Adams, T. S., Andrews, K. T., Coster, M. J., Edstein, M. D., MacKenzie, D., Charman, S. A., Koltun, M., Blundell, S., Campbell, A., Pouwer, R. H., Quinn, R. J., Beattie, K. D., Healy, P. C., \& Davis, R. A. (2015). Synthesis and antimalarial evaluation of amide and urea derivatives based on the thiaplakortone A natural product scaffold. Organic and Biomolecular Chemistry, 13(5), 1558-1570. https://doi.org/10.1039/c4ob01849d

Seth, P. P., Ranken, R., Robinson, D. E., Osgood, S. A., Risen, L. M., Rodgers, E. L., Migawa, M. T., Jefferson, E. A., \& Swayze, E. E. (2004). Aryl urea analogs with broad-spectrum antibacterial activity. Bioorganic and Medicinal Chemistry Letters, 14(22), 5569-5572. 
https://doi.org/10.1016/j.bmcl.2004.08.059

Šimek, M., Grünwaldová, V., \& Kratochvíl, B. (2014). Hot-stage microscopy for determination of api particles in a formulated tablet. BioMed Research International, 2014, 1-6. https://doi.org/10.1155/2014/832452

Upadhayaya, R. S., Kulkarni, G. M., Vasireddy, N. R., Vandavasi, J. K., Dixit, S. S., Sharma, V., \& Chattopadhyaya, J. (2009). Design, synthesis and biological evaluation of novel triazole, urea and thiourea derivatives of quinoline against Mycobacterium tuberculosis. Bioorganic and Medicinal Chemistry, 17(13), 4681-4692. https://doi.org/10.1016/j.bmc.2009.04.069

Vega-Pérez, J. M., Periñán, I., Argandoña, M., Vega-Holm, M., Palo-Nieto, C., Burgos-Morón, E., López-Lázaro, M., Vargas, C., Nieto, J. J., \& Iglesias-Guerra, F. (2012). Isoprenyl-thiourea and urea derivatives as new farnesyl diphosphate analogues: Synthesis and in vitro antimicrobial and cytotoxic activities. European Journal of Medicinal Chemistry, 58, 591612. https://doi.org/10.1016/j.ejmech.2012.10.042

Wang, X., \& Andrews, L. (2006). Infrared Spectra of M(OH) 1,2,3 (M = Mn, Fe, Co, Ni) Molecules in Solid Argon and the Character of First Row Transition Metal Hydroxide Bonding. The Journal of Physical Chemistry A, 110(33), 10035-10045. https://doi.org/10.1021/jp0624698

Xu, H., Faber, C., Uchiki, T., Racca, J., \& Dealwis, C. (2006). Structures of eukaryotic ribonucleotide reductase I define gemcitabine diphosphate binding and subunit assembly. Proceedings of the National Academy of Sciences, 103(11), 4028-4033. https://doi.org/10.1073/pnas.0600440103

Yamashita, S., Furubayashi, T., Kataoka, M., Sakane, T., Sezaki, H., \& Tokuda, H. (2000). Optimized conditions for prediction of intestinal drug permeability using Caco-2 cells. European Journal of Pharmaceutical Sciences, 10(3), 195-204. https://doi.org/10.1016/S0928-0987(00)00076-2

Yang, W., Hu, Y., Yang, Y. S., Zhang, F., Zhang, Y. Bin, Wang, X. L., Tang, J. F., Zhong, W. Q., \& Zhu, H. L. (2013). Design, modification and 3D QSAR studies of novel naphthalincontaining pyrazoline derivatives with/without thiourea skeleton as anticancer agents. Bioorganic and Medicinal Chemistry, 21(5), 1050-1063. https://doi.org/10.1016/j.bmc.2013.01.013

Yao, J., Chen, J., He, Z., Sun, W., \& Xu, W. (2012). Design, synthesis and biological activities of thiourea containing sorafenib analogs as antitumor agents. Bioorganic and Medicinal Chemistry, 20(9), 2923-2929. https://doi.org/10.1016/j.bmc.2012.03.018

Yee, S. (1997). In vitro permeability across caco-2 cells (colonic) can predict in vivo (small intestinal) absorption in man-fact or myth. Pharmaceutical Research, 14(4), 763-766.

Zhao, Y. H., Le, J., Abraham, M. H., Hersey, A., Eddershaw, P. J., Luscombe, C. N., Boutina, D., Beck, G., Sherborne, B., Cooper, I., \& Platts, J. A. (2001). Evaluation of human intestinal absorption data and subsequent derivation of a quantitative structure-activity relationship (QSAR) with the Abraham descriptors. Journal of Pharmaceutical Sciences, 90(6), 749-784. https://doi.org/10.1002/jps.1031 
Pharmaciana Vol. 11, No. 1, March 2021, Page. 1 - 14 